\title{
First results of the "Lean European Open Survey on SARS-CoV-2-Infected Patients (LEOSS)"
}

\author{
Carolin E. M. Jakob ${ }^{1,2} \cdot$ Stefan Borgmann ${ }^{3} \cdot$ Fazilet Duygu $^{4} \cdot$ Uta Behrends $^{2,5,6} \cdot$ Martin Hower $^{7} \cdot$ Uta Merle $^{8}$. \\ Anette Friedrichs $^{9} \cdot$ Lukas Tometten $^{10} \cdot$ Frank Hanses $^{11} \cdot$ Norma Jung $^{1} \cdot$ Siegbert Rieg $^{12} \cdot$ Kai Wille $^{13}$. \\ Beate Grüner ${ }^{14}$. Hartwig Klinker ${ }^{15}$. Nicole Gersbacher-Runge ${ }^{16}$. Kerstin Hellwig ${ }^{17}$. Lukas Eberwein ${ }^{18}$. \\ Sebastian Dolff ${ }^{19}$. Dominic Rauschning ${ }^{20}$. Michael von Bergwelt-Baildon ${ }^{21,22,23}$. Julia Lanznaster ${ }^{24}$. \\ Richard Strauß ${ }^{25}$. Janina Trauth ${ }^{26} \cdot$ Katja de With $^{27}$ - Maria Ruethrich ${ }^{28}$. Catherina Lueck ${ }^{29}$. Jacob Nattermann ${ }^{2,30}$. \\ Lene Tscharntke $^{1} \cdot$ Lisa Pilgram $^{32} \cdot$ Sandra Fuhrmann $^{1}$ - Annika Classen ${ }^{1,2} \cdot$ Melanie Stecher $^{1,2} \cdot$ Maximilian Schons $^{1}$. \\ Christoph Spinner ${ }^{2,31}$. Jörg Janne Vehreschild ${ }^{1,2,32}$
}

Received: 25 May 2020 / Accepted: 1 August 2020 / Published online: 1 October 2020

(c) The Author(s) 2020

\begin{abstract}
Purpose Knowledge regarding patients' clinical condition at severe acute respiratory syndrome coronavirus 2 (SARS-CoV-2) detection is sparse. Data in the international, multicenter Lean European Open Survey on SARS-CoV-2-Infected Patients (LEOSS) cohort study may enhance the understanding of COVID-19.

Methods Sociodemographic and clinical characteristics of SARS-CoV-2-infected patients, enrolled in the LEOSS cohort study between March 16, 2020, and May 14, 2020, were analyzed. Associations between baseline characteristics and clinical stages at diagnosis (uncomplicated vs. complicated) were assessed using logistic regression models.

Results We included 2155 patients, $59.7 \%(1,287 / 2,155)$ were male; the most common age category was $66-85$ years (39.6\%; 500/2,155). The primary COVID-19 diagnosis was made in $35.0 \%(755 / 2,155)$ during complicated clinical stages. A significant univariate association between age; sex; body mass index; smoking; diabetes; cardiovascular, pulmonary, neurological, and kidney diseases; ACE inhibitor therapy; statin intake and an increased risk for complicated clinical stages of COVID-19 at diagnosis was found. Multivariable analysis revealed that advanced age [46-65 years: adjusted odds ratio (aOR): $1.73,95 \%$ CI $1.25-2.42, p=0.001 ; 66-85$ years: aOR $1.93,95 \%$ CI $1.36-2.74, p<0.001 ;>85$ years: aOR $2.38,95 \%$ CI 1.49-3.81, $p<0.001$ vs. individuals aged 26-45 years], male sex (aOR 1.23, 95\% CI 1.01-1.50, $p=0.040$ ), cardiovascular disease (aOR 1.37, 95\% CI 1.09-1.72, $p=0.007$ ), and diabetes (aOR 1.33, 95\% CI 1.04-1.69, $p=0.023$ ) were associated with complicated stages of COVID-19 at diagnosis.

Conclusion The LEOSS cohort identified age, cardiovascular disease, diabetes and male sex as risk factors for complicated disease stages at SARS-CoV-2 diagnosis, thus confirming previous data. Further data regarding outcomes of the natural course of COVID-19 and the influence of treatment are required.
\end{abstract}

Keywords SARS-CoV-2 $\cdot$ COVID-19 $\cdot$ LEOSS $\cdot$ Cohort study

Christoph Spinner and Jörg Janne Vehreschild are shared last and contributed equally to this study.

Electronic supplementary material The online version of this article (https://doi.org/10.1007/s15010-020-01499-0) contains supplementary material, which is available to authorized users.

Jörg Janne Vehreschild

joerg.vehreschild@uk-koeln.de

Extended author information available on the last page of the article

\section{Introduction}

Since December 2019, the severe acute respiratory syndrome coronavirus 2 (SARS-CoV-2) originating in the Chinese city of Wuhan, located in Hubei Province, has spread globally and rapidly developed into a global pandemic $[1,2]$.

A comprehensive descriptive analysis of Chinese patients suffering from coronavirus disease (COVID-19) was published after processing the demographic data of 72,314 cases recorded by the Chinese Centers for Disease Control and 
Prevention [3]. The published study, in addition to other studies, identified risk factors for an advanced course of disease. The risk factors identified were age, male gender, higher body mass index (BMI), diabetes mellitus, and cardiovascular disease. Laboratory parameters such as elevated cytokine levels and altered coagulation parameters were discussed as indicators of possible hospitalization or disease severity. These parameters have been described extensively [4-12]. Many cohort studies have presented results about associating factors using data of single hospitals $[9,13]$, collaborations within a city [14] or a country [8,11, 15-17], or transnational collaborations $[10,18,19]$. The population of studies is heterogeneous and only few data on large European transregional cohorts of SARS-CoV-2-infected patients exist, so far.

These publications provide important insights to improve the clinical management of the patients, but more comprehensive, large, transregional cohort data are urgently needed to identify the clinical characteristics of the infected patients. Information on possible epidemiological or clinical risk factors is still scarce.

Using an extensive database on the clinical course of disease, data from the international Lean European Open Survey on SARS-Infected Patients (LEOSS) cohort may improve understanding of the heterogeneous clinical course and risk factors of SARS-CoV-2-infected patients and effective management strategies to treat this infection. This analysis focuses on baseline characteristics and the clinical disease stage of the patients at the time of COVID-19 diagnosis.

\section{Methods}

\section{Study design and patient cohort}

This analysis includes data of patients with confirmed SARS-CoV-2 infection (positive reverse transcriptase polymerase chain reaction (PCR) results), who received care at a LEOSS partner site (as inpatient or outpatient) between March 16, 2020, and May 14, 2020. Only patients with information available on follow-up and at the end of the treatment (recovery or death) were included in the analysis. An overview of recorded data in LEOSS is displayed in Fig. 1.

\section{Clinical data and endpoint}

In our analysis, we considered baseline data available closest to the time of first positive SARS-CoV-2 test within $48 \mathrm{~h}$. We examined patient characteristics (age, gender, BMI, smoking status, comorbidities, pre-existing Angiotensinconverting-enzyme inhibitors (ACE inhibitors), angiotensin II type 1 (AT1) receptor antagonists, statins, ibuprofen, and immunosuppressants intake, such as drugs for treatment of cancer, rheumatologic/inflammatory diseases, chronic inflammatory bowel disease, multiple sclerosis, etc.), vital parameters (body temperature, pulse, respiratory rate, oxygen saturation, oxygen, and carbon dioxide partial pressure), and laboratory parameters of acute phase and organ functions as well as soluble inflammation parameters. The primary endpoint was defined as a complicated clinical stage at initial presentation (time of first SARS-CoV-2 PCR-positive test result). A complicated clinical stage was defined by clinical findings (see Fig. 1) that indicate a clinical stage that requires medical treatment.

Parameters were documented categorically. Comorbidities were additionally dichotomized as cardiovascular disease (myocardial infarction, aortic stenosis, atrioventricular (AV) block, carotid arterial disease, chronic heart and circulation failure, peripheral vascular disease, hypertension, atrial fibrillation, coronary artery disease), pulmonary disease (chronic obstructive pulmonary disease, asthma, other chronic pulmonary diseases), hematological/oncological disease (leukemia, lymphoma, solid tumor, stem cell transplantation), diabetes mellitus (with and without end organ damage), kidney disease (acute kidney injury at time of SARS-CoV-2 detection, chronic kidney disease), neurological diseases (hemiplegia, dementia, cerebrovascular disease, stroke, transient ischemic attack, motoneuron diseases, movement disorder, multiple sclerosis, myasthenia gravis, neuromyelitis optica spectrum disorder, other neurological autoimmune diseases, other prior neurological diagnosis), others (connective tissue disease, peptic ulcer disease, chronic liver disease, liver cirrhosis, organ transplantation, rheumatic disease, HIV/AIDS). A comorbidity was defined as present if a minimum of one specific comorbidity was documented. Comorbidities were set to unknown/missing when all specific comorbidities of one group were unknown or missing. Values documented as unknown were defined as missing.

\section{Ethical statement}

Data were recorded completely anonymous and no patientidentifying data were stored. Written patient informed consent was waived. Metric parameters were categorized, and granular time-varying data (not included in this study) were aggregated over the duration of specific COVID-19 stages. Approval for LEOSS was obtained by the applicable local ethics committees of all participating centers and registered at the German Clinical Trails Register (DRKS, No. S00021145).

\section{Statistical analysis}

We calculated and reported patient characteristics as absolute numbers and percentages. Associations between clinical 
which was developed by the University Hospital of Cologne (UHC). ClinicalSurveys.net was hosted by QuestBack, Oslo, Norway on servers of UHC, Cologne, Germany, as part of a software-as-a-service agreement. Data were processed on the servers of UHC. Data management, statistical analysis, and computation of figures were conducted using $\mathrm{R}(\mathrm{R}$ Development Core Team, Vienna, Austria, Version 3.5.2., 2019). Additional information about the LEOSS questionnaire can be found under https://leoss.net/.

\section{Results}

\section{Cohort population}

We included 2155 patients from university hospitals (58.2\%; $1254 / 2155)$, non-university hospitals (36.4\%; 784/2155), and general practitioners $(5.4 \% ; 117 / 2155)$. Data were collected at 112 European study sites, mainly from Germany (98.1\%; 2113/2155), and Austria, Belgium, Italy, Switzerland, Latvia, Spain, Bosnia and Herzegovina, as well as Turkey. The median number of documented patients per study site was 5 , with a minimum of 1 and a maximum of 162 documented patients. Most patients were Caucasian (95.6\%; 1738/1818) and had an inpatient stay (92.8\%; 1829/1971). Almost one-tenth of patients were documented as having an asymptomatic SARS-CoV-2 infection (9.9\%; 161/1629). Patient characteristics are summarized in Table 1. Asymptomatic patients compared to all patients had more often documented comorbidities (see Supplements Table 1). This could be the reason that they were monitored without symptoms. The median estimated duration from SARS-CoV-2 infection to the day of the first SARS-CoV-2 PCR-positive test result was seven days (interquartile range; IQR: 5-11 days). Females were predominant in the age category $15-25$ years $(66.1 \% ; 39 / 59)$ and $>85$ years $(62.3 \% ; 99 / 159)$. Males were most predominant in the age category $46-65$ years $(67.3 \%$; 499/741). The age-gender distribution is displayed in Fig. 2.

\section{Vital and laboratory parameters}

In $61.1 \%(1002 / 1641)$ of patients, the body temperature was below $38.0{ }^{\circ} \mathrm{C}$ within $48 \mathrm{~h}$ subsequent to the day of SARSCoV-2 detection (could be in- or outpatient). The respiratory rate exceeded 21 breaths per minute in $32.1 \%$ (378/1178) of available cases on the day of SARS-CoV-2 detection. Oxygen saturation was below $90 \%$ in $16.9 \%$ (2268/1584) and the pulse rate exceeded 120 beats per minute in $4.8 \%(77 / 1603)$ of patients on the day of SARS-CoV-2 detection.

Figure 3 shows the vital and laboratory parameters at the time of SARS-CoV-2 detection. Serum ferritin levels were above $300 \mu \mathrm{g} / \mathrm{L}$ in $72.5 \%$ (464/640) of patients with available values, C-reactive protein (CRP) was above
$29 \mathrm{mg} / \mathrm{L}$ in $48.5 \%(759 / 1566)$, procalcitonin (PCT) was above $0.005 \mu \mathrm{g} / \mathrm{L}$ in $89.5 \%$ (716/800), interleukin-6 (IL6) was above $49 \mathrm{pg} / \mathrm{mL}$ in $41.3 \%$ (238/576). Fibrinogen was elevated in $60.2 \%$ patients $(241 / 400)$, lactate dehydrogenase $(\mathrm{LDH})$ in $65.1 \%(915 / 1405)$, as well as d-dimer in $38.8 \%$ (334/861) and was above the normal range of the respective local laboratory. The percentage of patients diagnosed in a complicated clinical stage of the disease and CRP values below $30 \mathrm{mg} / \mathrm{L}$ was $36.3 \%$ (222/612).

Possible surrogate markers of COVID-19 hepatopathy were higher in patients with SARS-CoV-2 infection than the age-adjusted normal value of the respective local laboratory: Aspartate aminotransferase (AST) in 39.6\% (544/1372), alanine aminotransferase (ALT) in 26.6\% (371/1396), and gamma-GT in $38.0 \%(502 / 1318)$. The hematologic parameters at the time of SARS-CoV-2 detection were as follows: leukocytes: $<3999$ cells $/ \mu \mathrm{L}$ in $17.2 \%$ (270/1573), $4000-11999 / \mu \mathrm{L}$ in $73.2 \%(1152 / 1573) \geq 12,000 / \mu \mathrm{L}$ in 9.6\% (151/1573) of patients; lymphocytes: $<799$ cells/ $\mu \mathrm{L}$ in $39.9 \%(487 / 1221)$ and $\geq 800$ cells $/ \mu \mathrm{L}$ in $61.2 \%$ $(747 / 1221)$ of patients. Platelets: $<199,999$ cells $/ \mu \mathrm{L}$ in $11.9 \%$ (186/1559), $120,000-449,999$ cells $/ \mu \mathrm{L}$ in $84.9 \%$ $(1323 / 1559)$, and $\geq 450,000$ cells/ $\mu \mathrm{L}$ in $2.2 \%$ (43/1559) of patients.

\section{Characteristics for clinical stage at SARS-CoV-2 detection}

At the time of SARS-CoV-2 detection, 35.0\% (755/2155) of patients, of whom $0.8 \%$ (6/755) were younger than 25 years, were already in a complicated clinical stage. Of those, the majority were male $(63.3 \%$; 478/755) and between 66 and 85 years of age $(46.8 \% ; 353 / 755)$. A total of $11.9 \%(55 / 463)$ and $16.5 \%(51 / 309)$ of patients in the complicated clinical stage at SARS-CoV-2 detection had a BMI of $>35 \mathrm{~kg} / \mathrm{m}^{2}$ and documented active smoking, respectively. All documented comorbidities and all pre-existing medications, except underlying hematologic and/or oncologic disease, ibuprofen, and any immunosuppressants were more often reported for patients with a complicated rather than an uncomplicated clinical stage of disease at SARS-CoV-2 detection (Table 1). The proportion of documented intake of ACE inhibitors of patients with cardiovascular diseases was for patients in an uncomplicated or complicated clinical stage at SARS-CoV-2 detection 31.4\% (uncomplicated: 206/656; complicated: 137/436) and considering only patients aged $>45$ years, $32.1 \%(201 / 626)$ and $31.4 \%$ 135/430), respectively.

Univariate regression results are shown in Table 2. The multivariable regression model was adjusted for age, gender, underlying cardiovascular diseases, diabetes mellitus, and pulmonal diseases (Table 2). We identified that advanced age, compared to individuals between 26 and 45 years of age, was 
Table 1 Baseline characteristics of patients in an uncomplicated or complicated stage of disease at day of positive SARS-CoV-2 detection

\begin{tabular}{|c|c|c|c|}
\hline & Total & $\begin{array}{l}\text { Uncomplicated clinical stage at day } \\
\text { of positive SARS-CoV-2 detection }\end{array}$ & $\begin{array}{l}\text { Complicated clinical stage at day } \\
\text { of positive SARS-CoV-2 detection }\end{array}$ \\
\hline Included cases & 2155 & $65 \%(1400 / 2155)$ & $35 \%(755 / 2155)$ \\
\hline \multicolumn{4}{|l|}{ Age (years) } \\
\hline$\leq 14$ & $1.2 \%(26 / 2155)$ & $1.6 \%(23 / 1400)$ & $0.4 \%(3 / 755)$ \\
\hline $15-25$ & $2.7 \%(59 / 2155)$ & $4.0 \%(56 / 1400)$ & $0.4 \%(3 / 755)$ \\
\hline $26-45$ & $14.7 \%(317 / 2155)$ & $18.0 \%(252 / 1400)$ & $8.6 \%(65 / 755)$ \\
\hline $46-65$ & $34.4 \%(741 / 2155)$ & $34.5 \%(483 / 1400)$ & $34.2 \%(258 / 755)$ \\
\hline $66-85$ & $39.6 \%(500 / 2155)$ & $35.7 \%(500 / 1400)$ & $46.8 \%(353 / 755)$ \\
\hline$>85$ & $7.4 \%(159 / 2155)$ & $6.1 \%(86 / 1400)$ & $9.7 \%(73 / 755)$ \\
\hline \multicolumn{4}{|l|}{ Sex } \\
\hline Female & $40.3 \%(868 / 2155)$ & $42.2 \%(591 / 1182)$ & $36.7 \%(277 / 554)$ \\
\hline Male & $59.7 \%(1287 / 2155)$ & $57.8 \%(809 / 1400)$ & $63.3 \%(478 / 956)$ \\
\hline \multicolumn{4}{|l|}{ Body mass index $\left(\mathrm{kg} / \mathrm{m}^{2}\right)$} \\
\hline$<18.5$ & $3.0 \%(36 / 1187)$ & $3.3 \%(24 / 724)$ & $2.6 \%(12 / 463)$ \\
\hline $18.5-24.9$ & $36.6 \%(434 / 1187)$ & $39.5 \%(286 / 724)$ & $32.0 \%(148 / 463)$ \\
\hline $25-29.9$ & $36.1 \%(428 / 1187)$ & $36.2 \%(262 / 724)$ & $35.9 \%(166 / 463)$ \\
\hline $30-34.9$ & $15.7 \%(186 / 1187)$ & $14.4 \%(104 / 724)$ & $17.7 \%(82 / 463)$ \\
\hline$\geq 35$ & $8.7 \%(103 / 1187)$ & $6.6 \%(48 / 724)$ & $11.9 \%(55 / 463)$ \\
\hline \multicolumn{4}{|l|}{ Smoking } \\
\hline Active smoking & $13.8 \%(143 / 1040)$ & $12.6 \%(92 / 731)$ & $16.5 \%(51 / 309)$ \\
\hline Former smoking & $15.1 \%(157 / 1040)$ & $13.5 \%(99 / 731)$ & $18.8 \%(58 / 309)$ \\
\hline Nonsmoking & $71.2 \%(740 / 1040)$ & $73.9 \%(540 / 731)$ & $64.7 \%(200 / 309)$ \\
\hline \multicolumn{4}{|l|}{ Comorbidities } \\
\hline Cardiovascular disease & $55.7 \%(1158 / 2079)$ & $49.9 \%(678 / 1358)$ & $66.6 \%(480 / 721)$ \\
\hline Diabetes mellitus & $18.4 \%(385 / 2090)$ & $15.4 \%(210 / 1367)$ & $24.2 \%(175 / 723)$ \\
\hline Pulmonary disease & $14.9 \%(307 / 2059)$ & $13.4 \%(179 / 1336)$ & $17.7 \%(128 / 723)$ \\
\hline Hematological and/or oncological disease & $14.6 \%(305 / 2087)$ & $14.6 \%(200 / 1367)$ & $14.6 \%(105 / 720)$ \\
\hline Neurological disease & $21.5 \%(411 / 1911)$ & $19.5 \%(245 / 1257)$ & $25.4 \%(166 / 654)$ \\
\hline Kidney disease & $14.6 \%(305 / 2088)$ & $12.7 \%(173 / 1366)$ & $18.3 \%(132 / 722)$ \\
\hline Other comorbidities* & $12.0 \%(243 / 2021)$ & $12.4 \%(164 / 1319)$ & $11.3 \%(79 / 702)$ \\
\hline \multicolumn{4}{|c|}{ Pre-existing medication at day of positive SARS-CoV-2 test } \\
\hline ACE inhibitors & $18.1 \%(364 / 2008)$ & $16.2 \%(216 / 1332)$ & $21.9 \%(148 / 676)$ \\
\hline AT-1-receptor antagonists & $17.2 \%(345 / 2000)$ & $16.3 \%(217 / 1330)$ & $19.1 \%(128 / 670)$ \\
\hline Statins & $23.2 \%(335 / 1441)$ & $21.1 \%(200 / 946)$ & $27.3 \%(135 / 495)$ \\
\hline Ibuprofen & $4.1 \%(78 / 1918)$ & $4.7 \%(60 / 1274)$ & $2.8 \%(18 / 644)$ \\
\hline \multicolumn{4}{|c|}{ Pre-existing medication until three months before positive SARS-CoV-2 test } \\
\hline Any immunosuppressive medication & $10.3 \%(189 / 1841)$ & $11.0 \%(132 / 1202)$ & $8.9 \%(57 / 639)$ \\
\hline
\end{tabular}

ACE inhibitors angiotensin-converting-enzyme inhibitor, AT-1-receptor antagonists angiotensin II type 1 (AT1) receptor antagonists. Other comorbidities-connective tissue disease, peptic ulcer disease, chronic liver disease, liver cirrhosis, organ transplantation, rheumatic disease, HIV/AIDS

significantly associated with a higher risk for a complicated clinical stage at SARS-CoV-2 detection (46-65 years: adjusted OR; aOR $1.73,95 \%$ CI $1.25-2.42, p=0.001 ; 66-85$ years: aOR $1.93,95 \%$ CI $1.36-2.74, p \leq 0.001 ;>85$ years: aOR $2.38,95 \%$ CI $1.49-3.81, p \leq 0.001,15-25$ years: aOR 0.23 , $95 \%$ CI $0.05-0.65, p=0.016, \leq 14$ years: aOR $0.55,95 \%$ CI $0.13-1.66, p=0.344)$. Underlying cardiovascular diseases (aOR 1.37, 95\% CI 1.09-1.72, $p=0.007$ ), diabetes mellitus (aOR 1.33, 95\% CI 1.04-1.69, $p=0.023$ ), and male gender
(aOR $1.23,95 \%$ CI $1.01-1.50, p=0.040$ ) were also significantly associated with a complicated clinical stage at SARSCoV-2 detection. 


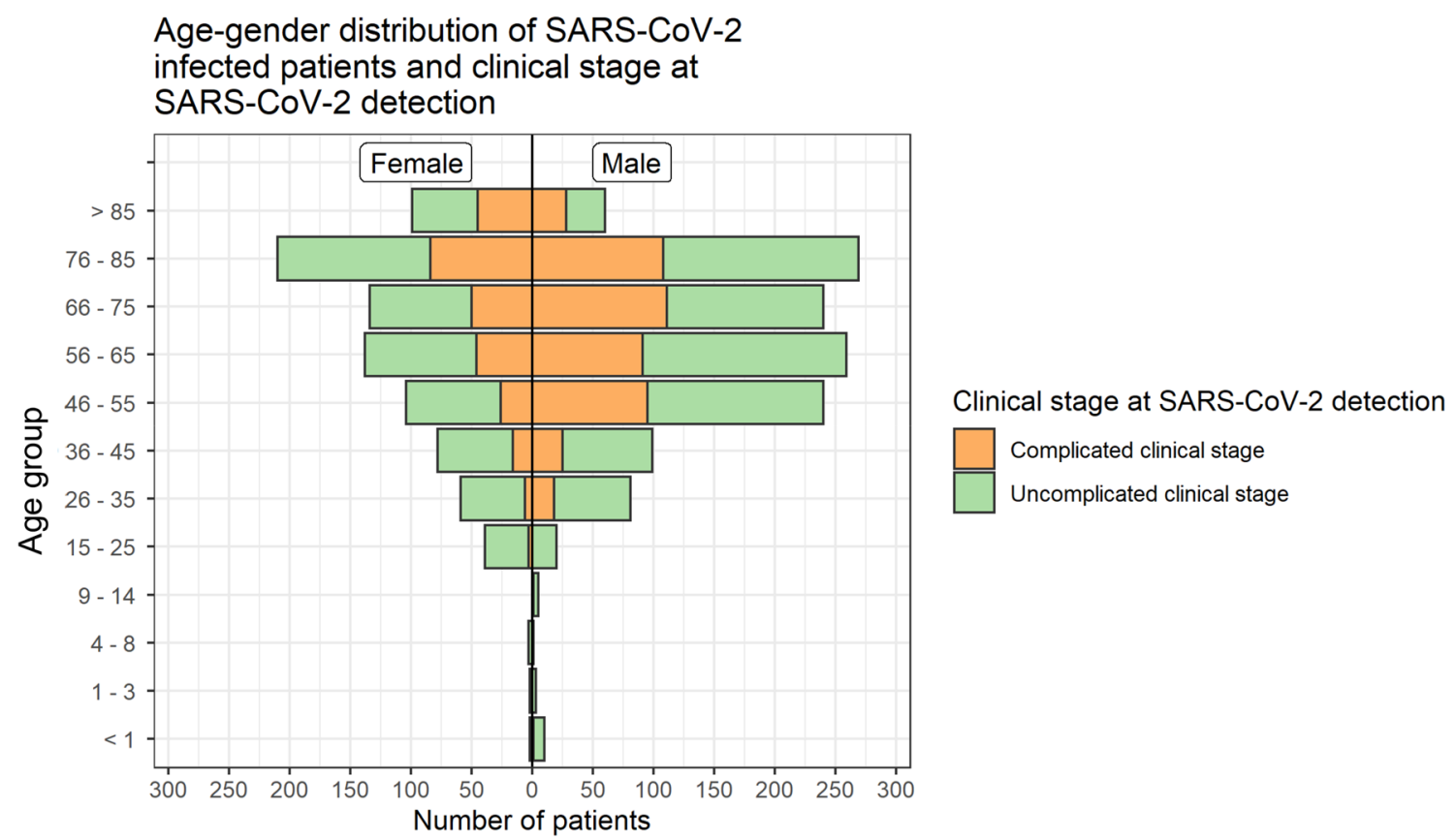

Fig. 2 Age-gender distribution and clinical stage at time of SARS-CoV-2 detection. The bars are divided according to the clinical condition at time of SARS-CoV-2 detection (uncomplicated vs. complicated). The number of individuals in the total population is 2155

\section{Discussion}

In this European study, we assessed the clinical characteristics of SARS-CoV-2-infected patients who required medical care and determined associating factors for complicated clinical stages at the time of SARS-CoV-2 detection (severity of COVID-19 at diagnosis). In comparison with previous reports, we identified predominant characteristics including male gender, and underlying cardiovascular diseases, diabetes mellitus, and pulmonary diseases [5, 7-10, 20, 21]. In addition, neurological diseases were predominant in our cohort.

In line with the published data, our observation confirms that inflammatory parameters are likely to be elevated at the time of SARS-CoV-2 detection $[9,22]$. In our cohort, we only found an elevation of CRP $>29 \mathrm{mg} / \mathrm{L}$ in almost two-third of patients in a complicated clinical stage at time of COVID-19 diagnosis. However, our endpoint included pulmonary and extrapulmonary clinical findings. Patients without pneumonia were also defined as complicated clinical stage at time of COVID-19 diagnosis which could explain the less frequent increase in CRP. Further analysis on clinical course and outcome data might elucidate the potential prognostic significance of acute phase proteins such as ferritin and procalcitonin [4, 9, 23]. Body temperature at the time of SARS-CoV-2 detection was less frequently elevated in our cohort than observed in other studies assessing hospitalized patients [5, 7]. However, our cohort also included hospitalized patients whose admission was not related to COVID-19. Almost onetenth of patients were asymptomatic. This finding demands further follow-up analyses in our cohort regarding clinical course and outcome. However, we detected elevated respiratory rates at days of positive SARS-CoV-2 testing which is adequate for a hospital setting $[5,20]$ and tends to be an important monitoring parameter.

As stated in other studies [21], over one-third of patients were diagnosed with COVID-19 in a complicated clinical stage. In line with other studies that examined risk factors for COVID-19 disease progression, we identified a significant univariate association between advanced age; male gender; adiposity; smoking; cardiovascular, pulmonary, and kidney diseases; and diabetes mellitus and complicated clinical stages at SARS-CoV-2 detection [5, 8, 9, 20, 24].

When comparing the observed significant univariate association of neurological diseases with complicated clinical stages at SARS-CoV-2 detection, the heterogeneity of the specific diseases defined as neurological diseases in this study should be considered. Furthermore, one must be cautious with the interpretation of the significant univariant factors such as pre-existing statin, ACE inhibitors, and ibuprofen intake on the day of SARS-CoV-2 detection. In the covariate adjusted model, these parameters were excluded due to decrease in model quality (increase of information loss). Additionally, other studies confirmed that pre-existing ACE inhibitors or ibuprofen intake are possibly not the factors causing severity of COVID-19 [16, 25-27]. However, 
Fig. 3 Clinical-chemical laboratory parameters and vital parameters at the time of SARS$\mathrm{CoV}-2$ detection. Relative proportions to the measured/ collected parameters are shown (missing values were excluded). The colors (green to red) express an increase in impairment from the normal to slightly impaired range (green) to critically impaired (red). Normal values are $\mathrm{CRP}<5 \mathrm{mg} / \mathrm{l}$; ferritin male $<300$, females $<150 \mu \mathrm{g} / \mathrm{l}$; PCT $<0.5$ ng/l; IL6 $<10$ pg/ $\mathrm{ml}$; oxygen saturation 96-100\%; oxygen partial pressure $\geq 80 \mathrm{mmHg}$; carbon dioxide partial pressure $35-45 \mathrm{mmHg}$; temperature $<37.3^{\circ} \mathrm{C}$; respiratory rate $<16$ per min. $C R P$ C-reactive protein, $P C T$ procalcitonin, IL6 interleukin-6, $L D H$ lactate dehydrogenase, $A L T$ alanine aminotransferase, $A S T$ aspartate aminotransferase, Gamma-GT gamma-glutamyl transferase, $U L N$ upper limit of normal in the respective local laboratory. The number of individuals in the total population is 2155
Laboratory parameters at SARS-CoV-2 detection

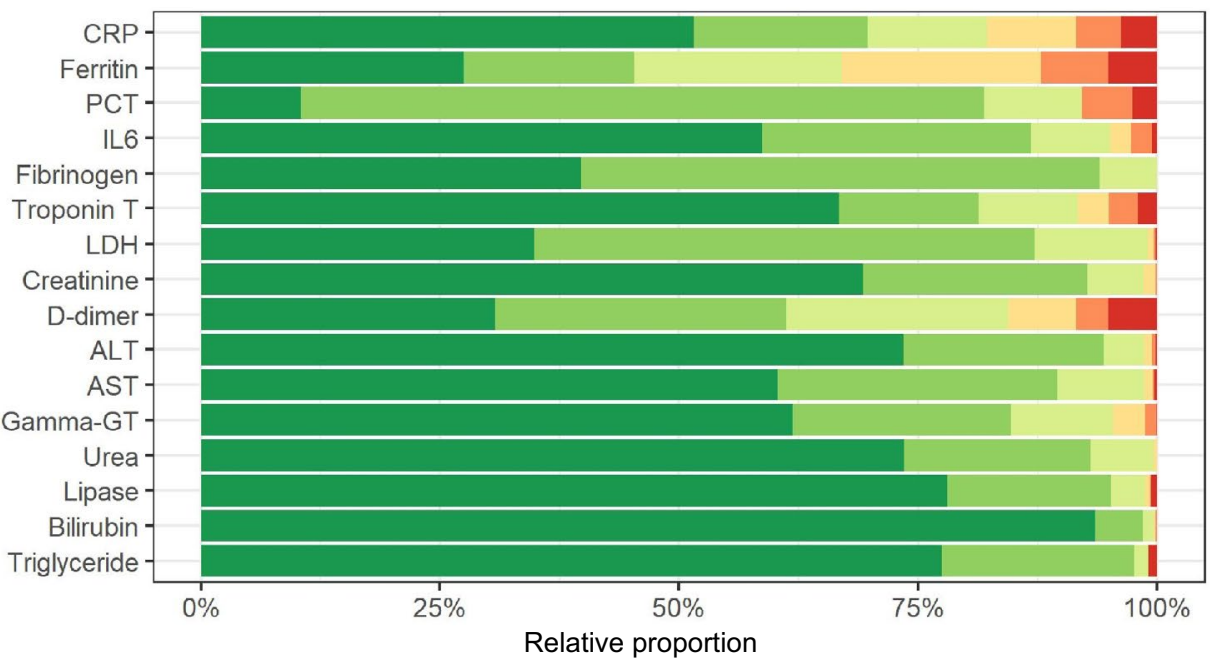

\begin{tabular}{|l|l|l|l|l|l|}
\hline & CRP $[\mathrm{mg} / \mathrm{l}]$ & Ferritin $[\mu \mathrm{g} / \mathrm{l}]$ & PCT $[\mu \mathrm{g} / \mathrm{l}]$ & IL6 $[\mathrm{pg} / \mathrm{ml}]$ & Other \\
\hline & $<30$ & $<300$ & $<0.005$ & $<50$ & normal \\
\hline & $30-69$ & $300-499$ & $0.006-0.5$ & $50-199$ & $>$ ULN \\
\hline & $70-119$ & $500-999$ & $0.51-2$ & $200-499$ & $>2 \times$ ULN \\
\hline & $120-179$ & $1000-1999$ & n.a. & $500-999$ & $>5 \times$ ULN \\
\hline & $180-250$ & $2000-4000$ & $2.1-10$ & $1000-5000$ & $>10 \times$ ULN \\
\hline$\square$ & $>250$ & $>4000$ & $>10$ & $>5000$ & $>20 x$ ULN \\
\hline
\end{tabular}

Vital parameters at SARS-CoV-2 detection

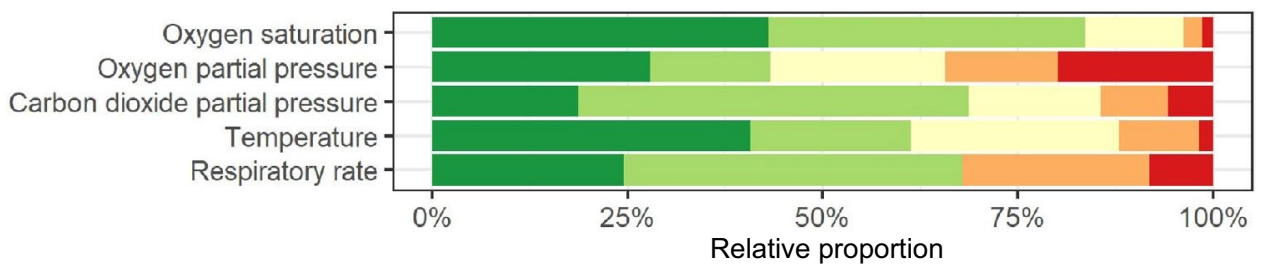

\begin{tabular}{|l|l|l|l|l|l|}
\hline & $\begin{array}{l}\text { Oxygen } \\
\text { saturation } \\
{[\%]}\end{array}$ & $\begin{array}{l}\text { Oxygen partial } \\
\text { pressure }[\mathrm{mmHg}]\end{array}$ & $\begin{array}{l}\text { Carbon dioxide } \\
\text { partial pressure } \\
{[\mathrm{mmHg}]}\end{array}$ & $\begin{array}{l}\text { Temperature } \\
{\left[{ }^{\circ} \mathrm{C}\right]}\end{array}$ & $\begin{array}{l}\text { Respiratory } \\
\text { rate }[\text { per min] }\end{array}$ \\
\hline $96-100$ & $\geq 80$ & $<30$ & $<37.3$ & $<16$ \\
\hline & $90-95$ & $70-79$ & $30-38$ & $37.3-37.9$ & $16-21$ \\
\hline $80-89$ & $60-69$ & $39-45$ & $38-38.9$ & n.a. \\
\hline $70-79$ & $50-59$ & $46-55$ & $39-39.9$ & $22-29$ \\
\hline$\square$ & $<70$ & $<50$ & $>55$ & $\geq 40$ & $\geq 30$ \\
\hline
\end{tabular}

there is a higher prevalence of cardiovascular diseases in patients with more severe COVID-19 illness [25].

Within a multivariable model, we found advanced age, male sex, underlying cardiovascular diseases, and diabetes mellitus as independent risk factors for complicated clinical disease at the time of diagnosis. Higher BMI and smoking as possible independent risk factors [9] were excluded due to multicollinearity. Further analysis would be necessary for incorporating dependencies of baseline characteristics to perform risk stratification.

This study analyzed associating factors for a complicated clinical stage at initial presentation (day of SARS-CoV-2 detection). The relation to severity of clinical course was not considered. Besides the clinical factors associated for a progressive disease more confounders might be important factors neglected in this study. Data on socioeconomics, insurance issues, access to health services, country specific testing capacities, testing policies or intrinsic motivation were not considered for this study. The mentioned factors could be correlated with a late diagnosis. Besides rapid COVID-19 progression, late diagnosis could be a reason for being in a complicated clinical stage at initial presentation.

Further limitations of our study include the limited number of patients considered in this study. Patients with a complicated clinical stage at SARS-CoV-2 detection could be underrepresented in this cohort, as more of these patients 
Table 2 Associations between baseline characteristics and complicated clinical stage at day of positive SARS-CoV-2 detection

\begin{tabular}{|c|c|c|c|c|}
\hline & \multicolumn{2}{|l|}{ Univariate model* } & \multicolumn{2}{|c|}{ Mutivariable model* } \\
\hline & OR $(95 \% \mathrm{CI})$ & $p$ value & $\mathrm{aOR}(95 \% \mathrm{CI})$ & $p$ value \\
\hline \multicolumn{5}{|l|}{ Age (years) } \\
\hline$\leq 14$ & $0.51(0.12-1.52)$ & 0.279 & $0.55(0.13-1.66)$ & 0.344 \\
\hline $15-25$ & $0.21(0.05-0.59)$ & 0.010 & $0.23(0.05-0.65)$ & 0.016 \\
\hline $26-45$ & ref. & ref. & ref. & ref. \\
\hline $46-65$ & $2.07(1.52-2.84)$ & $<0.001$ & $1.73(1.25-2.42)$ & 0.001 \\
\hline $66-85$ & $2.74(2.03-3.74)$ & $<0.001$ & $1.93(1.36-2.74)$ & $<0.001$ \\
\hline$>85$ & $3.29(2.18-4.99)$ & $<0.001$ & $2.38(1.49-3.81)$ & $<0.001$ \\
\hline \multicolumn{5}{|l|}{ Sex } \\
\hline Female & ref. & ref. & ref. & ref. \\
\hline Male & $1.26(1.05-1.51)$ & 0.013 & $1.23(1.01-1.50)$ & 0.040 \\
\hline \multicolumn{5}{|l|}{ Body mass index $\left(\mathrm{kg} / \mathrm{m}^{2}\right)$} \\
\hline$<18.5$ & $0.97(0.46-1.95)$ & 0.926 & $* *$ & $* *$ \\
\hline $18.5-24.9$ & ref. & ref. & ref. & ref. \\
\hline $25-29.9$ & $1.22(0.93-1.62)$ & 0.153 & $* *$ & $* *$ \\
\hline $30-34.9$ & $1.52(1.07-2.16)$ & 0.019 & $* *$ & $* *$ \\
\hline$>35$ & $2.21(1.43-3.43)$ & $<0.001$ & $* *$ & $* *$ \\
\hline \multicolumn{5}{|l|}{ Smoking } \\
\hline Active smoking & $1.50(1.02-2.18)$ & 0.037 & $* *$ & $* *$ \\
\hline Former smoking & $1.58(1.10-2.27)$ & 0.013 & $* *$ & $* *$ \\
\hline Nonsmoking & ref. & ref. & ref. & ref. \\
\hline \multicolumn{5}{|l|}{ Comorbidities $^{1}$} \\
\hline Cardiovascular disease & $2.00(1.66-2.41)$ & $<0.001$ & $1.37(1.09-1.72)$ & 0.007 \\
\hline Diabetes mellitus & $1.76(1.40-2.20)$ & $<0.001$ & $1.33(1.04-1.69)$ & 0.023 \\
\hline Pulmonary disease & $1.39(1.08-1.78)$ & 0.009 & $1.27(0.98-1.64)$ & 0.068 \\
\hline Hematological and/or oncological disease & $1.00(0.77-1.28)$ & 0.977 & $* * *$ & $* * *$ \\
\hline Neurological disease & $1.41(1.12-1.76)$ & 0.003 & $* * *$ & $* * *$ \\
\hline Kidney disease & $1.54(1.20-1.97)$ & $<0.001$ & $* * *$ & $* * *$ \\
\hline Other comorbidities & $0.89(0.67-1.18)$ & 0.438 & $* * *$ & $* * *$ \\
\hline \multicolumn{5}{|c|}{ Pre-existing medication at day of positive SARS-CoV-2 test ${ }^{1}$} \\
\hline ACE inhibitors & $1.45(1.15-1.83)$ & 0.002 & $* * *$ & $* * *$ \\
\hline AT-1-receptor antagonists & $1.21(0.95-1.54)$ & 0.120 & $* * *$ & $* * *$ \\
\hline Statins & $1.40(1.09-1.80)$ & 0.009 & $* * *$ & $* * *$ \\
\hline Ibuprofen & $0.58(0.33-0.97)$ & 0.047 & $* * *$ & $* * *$ \\
\hline \multicolumn{5}{|c|}{ Pre-existing medication until three months before positive SARS-CoV-2 test ${ }^{1}$} \\
\hline Any immunosuppressive medication & $0.79(0.57-1.09)$ & 0.166 & $* * *$ & $* * *$ \\
\hline
\end{tabular}

$n=134$ Observations were excluded from multivariable regression model due to missingness. ACE inhibitors angiotensin-converting-enzyme inhibitor, AT-1-receptor antagonists angiotensin II type 1 (AT1) receptor antagonists, Ref. reference group. Other comorbidities-connective tissue disease, peptic ulcer disease, chronic liver disease, liver cirrhosis, organ transplantation, rheumatic disease, HIV/AIDS

*Results from a logistic regression model displayed with odds ratios (ORs) and 95\% confidence intervals (CI); all variables were fitted simultaneously in the multivariable model

**Variable excluded from multivariable analysis due to multicollinearity

***Variable excluded from multivariable analysis due to model quality

${ }^{1}$ Reference group was not present/given require long medical observation and patient's outcome could more likely not be known at time of conduction of this analysis (inclusion criteria). The highest documentation rates were performed by university hospitals in larger cities; consequently, rural areas might be underrepresented.
Most patients were documented in Germany, and results may, therefore, not be transferable to all regions of Europe. Furthermore, many hospitals in Germany had the capacity to monitor patients with asymptomatic or mild SARS-CoV-2 infections which would not be applicable to all European 
hospitals. Patients were mainly recruited from hospitals, and a transferability to outpatient settings is therefore limited. Comorbidities and medication intake were collected as binary categories. We did not incorporate data on the extent of underlying comorbidity nor regarding dose nor the duration of treatment. Comorbidities were additionally dichotomized; we did not consider associations of specific underlying diseases, as, for example, hypertension for cardiovascular diseases.

\section{Conclusions}

To conclude, this comprehensive description identified characteristics of SARS-CoV-2-infected patients seeking medical care and determined associating factors for complicated clinical stages at diagnosis. The results indicated characteristics comparable to those observed in international published cohorts.

Acknowledgements We express our deep gratitude to all study teams supporting the LEOSS study. Further sites that contributed at least 5 per mille to the analyses of this study were: Tropenklinik Paul-Lechler Hospital Tübingen, Dr. Claudie Raichle; Praxis am Ebertplatz, Dr. Tim Kümmerle, Dr. Christoph Wyen; Maria-Hilf Hospital Mönchengladbach, Dr. Ingo Greiffendorf; Elbland Hospital Riesa, Prof. Dr. Jörg Schubert; Malteser Hospital St. Hildegardis, Dr. Caroline Kann; Petrus Hospital Wuppertal, Dr. Sven Stieglitz; University Hospital HamburgEppendorf, Dr. Sabine Jordan; University Hospital Düsseldorf, Dr. Timo Brandenburger; University Hospital Marien Hospital Herne, Dr. Beate Schultheis; Hospital Nürnberg Nord Nordklinikum, Dr. Sebastian Becker; Hospital Osnabrück, Annika Ritter; Robert Koch Institut, Dr. Christian Herz, Dr. Thomas Kratz; Hegau-Bodensee-Hospital Singen, Dr. Michael Schmid; Centre for Nephrology Villingen-Schwenningen, Prof. Dr. Bernd Hohenstein; Bethesda Hospital Bergedorf, Dr. Marc Bota; University Hospital Joseo Trueta, Dr. Gary Alvarez; St. Josefs-Hospital Wiesbaden, Dr. Michael Doll; Robert-Bosch-Hospital, Dr. Katja S. Rothfuß; Elisabeth-Hospital Essen, Dr. Ingo Voigt; Medical University Graz, Dr. Jürgen Prattes. We thank Bernd Franke, Nick Schulze, Gabriel Sauer, Yuki Brinker, and Angelina Menke for providing continuous support in the coordination and development of the LEOSS study. This study was supported by the German Center for Infection Research (DZIF) and the Willy Robert Pitzer Foundation.

Funding No funding was received for this study. Open Access funding provided by Projekt DEAL.

\section{Compliance with ethical standards}

Conflict of interest On behalf of all authors, the corresponding author states that there is no conflict of interest.

Open Access This article is licensed under a Creative Commons Attribution 4.0 International License, which permits use, sharing, adaptation, distribution and reproduction in any medium or format, as long as you give appropriate credit to the original author(s) and the source, provide a link to the Creative Commons licence, and indicate if changes were made. The images or other third party material in this article are included in the article's Creative Commons licence, unless indicated otherwise in a credit line to the material. If material is not included in the article's Creative Commons licence and your intended use is not permitted by statutory regulation or exceeds the permitted use, you will need to obtain permission directly from the copyright holder. To view a copy of this licence, visit http://creativecommons.org/licenses/by/4.0/.

\section{References}

1. World Health Organization. Coronavirus disease (COVID-19) outbreak situation. 2020. https://covid19.who.int/. Accessed 25 May 2020.

2. Cheng ZJ, Shan J. 2019 Novel coronavirus: where we are and what we know. Infection. 2020;48:155-63. https://doi.org/10.1007/ s15010-020-01401-y.

3. Wu Z, McGoogan JM. Characteristics of and important lessons from the coronavirus disease 2019 (COVID-19) outbreak in China: summary of a report of 72314 cases from the Chinese Center for Disease Control and Prevention. JAMA. 2020. https:// doi.org/10.1001/jama.2020.2648.

4. Zhou F, Yu T, Du R, Fan G, Liu Y, Liu Z, et al. Clinical course and risk factors for mortality of adult inpatients with COVID19 in Wuhan, China: a retrospective cohort study. Lancet. 2020;395:1054-62. https://doi.org/10.1016/S0140-6736(20)30566 -3 .

5. Wang D, Hu B, Hu C, Zhu F, Liu X, Zhang J, et al. Clinical characteristics of 138 hospitalized patients with 2019 novel coronavirus-infected pneumonia in Wuhan, China. JAMA. 2020. https:// doi.org/10.1001/jama.2020.1585.

6. Wu C, Chen X, Cai Y, Xia J, Zhou X, Xu S, et al. Risk factors associated with acute respiratory distress syndrome and death in patients with coronavirus disease 2019 pneumonia in Wuhan, China. JAMA Intern Med. 2020. https://doi.org/10.1001/jamai nternmed.2020.0994.

7. Chen N, Zhou M, Dong X, Qu J, Gong F, Han Y, et al. Epidemiological and clinical characteristics of 99 cases of 2019 novel coronavirus pneumonia in Wuhan, China: a descriptive study. Lancet. 2020;395:507-13. https://doi.org/10.1016/S0140-6736(20)30211 $-7$.

8. Grasselli G, Zangrillo A, Zanella A, Antonelli M, Cabrini L, Castelli A, et al. Baseline characteristics and outcomes of 1591 patients infected with SARS-CoV-2 admitted to ICUs of the Lombardy region, Italy. JAMA. 2020. https://doi.org/10.1001/ jama.2020.5394.

9. Petrilli CM, Jones SA, Yang J, Rajagopalan H, O’Donnell LF, Chernyak Y, et al. Factors associated with hospitalization and critical illness among 4103 patients with COVID-19 disease in New York City 2020. https://doi.org/10.1101/2020.04.08.20057 794.

10. International Severe Acute Respiratory and Emerging Infections Consortium (ISARIC). COVID-19 Report: 19 May 2020. 2020. https://media.tghn.org/medialibrary/2020/05/ISARIC_Data_Platf orm_COVID-19_Report_19MAY20.pdf. Accessed 25 May 2020.

11. COVID-19 National Emergency Response Center, Epidemiology and Case Management Team, Korea Centers for Disease Control and Prevention. Coronavirus disease-19: the first 7,755 cases in the Republic of Korea. Osong Public Health Res Perspect. 2020;11:85-90.

12. Chen Q, Zheng Z, Zhang C, Zhang X, Wu H, Wang J, et al. Clinical characteristics of 145 patients with corona virus disease 2019 (COVID-19) in Taizhou, Zhejiang, China. Infection. 2020;48:1-9. https://doi.org/10.1007/s15010-020-01432-5.

13. Helms J, Tacquard C, Severac F, Leonard-Lorant I, Ohana M, Delabranche $\mathrm{X}$, et al. High risk of thrombosis in patients with 
severe SARS-CoV-2 infection: a multicenter prospective cohort study. Intensive Care Med. 2020;46:1089-98. https://doi. org/10.1007/s00134-020-06062-x.

14. Cummings MJ, Baldwin MR, Abrams D, Jacobson SD, Meyer BJ, Balough EM, et al. Epidemiology, clinical course, and outcomes of critically ill adults with COVID-19 in New York City: a prospective cohort study. medRxiv. 2020. https://doi.org/10.1016/ S0140-6736(20)31189-2.

15. Lewnard JA, Liu VX, Jackson ML, Schmidt MA, Jewell BL, Flores JP, et al. Incidence, clinical outcomes, and transmission dynamics of severe coronavirus disease 2019 in California and Washington: prospective cohort study. BMJ. 2020;369:m1923. https://doi.org/10.1136/bmj.m1923.

16. Zhang P, Zhu L, Cai J, Lei F, Qin J-J, Xie J, et al. Association of inpatient use of angiotensin-converting enzyme inhibitors and angiotensin II receptor blockers with mortality among patients with hypertension hospitalized with COVID-19. Circ Res. 2020;126:1671-81. https://doi.org/10.1161/CIRCRESAHA .120.317134.

17. Docherty AB, Harrison EM, Green CA, Hardwick HE, Pius R, Norman L, et al. Features of 20133 UK patients in hospital with covid-19 using the ISARIC WHO clinical characterisation protocol: prospective observational cohort study. BMJ. 2020;369:m1985. https://doi.org/10.1136/bmj.m1985.

18. Götzinger F, Santiago-García B, Noguera-Julián A, Lanaspa M, Lancella L, Calò Carducci FI, et al. COVID-19 in children and adolescents in Europe: a multinational, multicentre cohort study. Lancet Child Adolesc Health. 2020. https://doi.org/10.1016/S2352 $-4642(20) 30177-2$.

19. Moon AM, Webb GJ, Aloman C, Armstrong MJ, Cargill T, Dhanasekaran R, et al. High mortality rates for SARS-CoV-2 infection in patients with pre-existing chronic liver disease and cirrhosis: preliminary results from an international registry. J Hepatol. 2020. https://doi.org/10.1016/j.jhep.2020.05.013.

20. Dreher M, Kersten A, Bickenbach J, Balfanz P, Hartmann B, Cornelissen C, et al. The characteristics of 50 hospitalized COVID-19 patients with and without ARDS. Dtsch Arztebl Int. 2020. https:// doi.org/10.3238/arztebl.2020.0271.

21. Richardson S, Hirsch JS, Narasimhan M, Crawford JM, McGinn $\mathrm{T}$, Davidson KW, et al. Presenting characteristics, comorbidities, and outcomes among 5700 patients hospitalized with COVID-19 in the New York city area. JAMA. 2020. https://doi.org/10.1001/ jama.2020.6775.

22. Wang L. C-reactive protein levels in the early stage of COVID19. Med Mal Infect. 2020. https://doi.org/10.1016/j.medma 1.2020.03.007.

23. Zhang J-J, Dong X, Cao Y-Y, Yuan Y-D, Yang Y-B, Yan Y-Q, et al. Clinical characteristics of 140 patients infected with SARSCoV-2 in Wuhan, China. Allergy. 2020. https://doi.org/10.1111/ all.14238.

24. Henry BM, Lippi G. Chronic kidney disease is associated with severe coronavirus disease 2019 (COVID-19) infection. Int Urol Nephrol. 2020. https://doi.org/10.1007/s11255-020-02451-9.

25. Mackey K, King VJ, Gurley S, Kiefer M, Liederbauer E, Vela K, et al. Risks and impact of angiotensin-converting enzyme inhibitors or angiotensin-receptor blockers on SARS-CoV-2 infection in adults. Ann Intern Med. 2020. https://doi.org/10.7326/M20-1515.

26. Reynolds HR, Adhikari S, Pulgarin C, Troxel AB, Iturrate E, Johnson SB, et al. Renin-angiotensin-aldosterone system inhibitors and risk of Covid-19. N Engl J Med. 2020;382:2441-8. https ://doi.org/10.1056/NEJMoa2008975.

27. Mancia G, Rea F, Ludergnani M, Apolone G, Corrao G. Reninangiotensin-aldosterone system blockers and the risk of Covid-19. N Engl J Med. 2020. https://doi.org/10.1056/NEJMoa2006923.

\section{Affiliations}

Carolin E. M. Jakob ${ }^{1,2} \cdot$ Stefan Borgmann ${ }^{3} \cdot$ Fazilet Duygu $^{4} \cdot$ Uta Behrends $^{2,5,6} \cdot$ Martin Hower $^{7} \cdot$ Uta Merle $^{8}$. Anette Friedrichs ${ }^{9} \cdot$ Lukas Tometten $^{10} \cdot$ Frank Hanses $^{11} \cdot$ Norma Jung $^{1} \cdot$ Siegbert Rieg ${ }^{12} \cdot$ Kai Wille $^{13}$. Beate Grüner ${ }^{14} \cdot$ Hartwig Klinker ${ }^{15} \cdot$ Nicole Gersbacher-runge $^{16} \cdot$ Kerstin Hellwig $^{17} \cdot$ Lukas Eberwein $^{18}$. Sebastian Dolff ${ }^{19}$. Dominic Rauschning ${ }^{20}$. Michael Von Bergwelt-Baildon ${ }^{21,22,23}$. Julia Lanznaster ${ }^{24}$. Richard Strauß $\beta^{25}$. Janina Trauth ${ }^{26} \cdot$ Katja de With $^{27} \cdot$ Maria Ruethrich $^{28}$ - Catherina Lueck ${ }^{29}$. Jacob Nattermann ${ }^{2,30}$. Lene Tscharntke ${ }^{1} \cdot$ Lisa Pilgram $^{32} \cdot$ Sandra Fuhrmann $^{1} \cdot$ Annika Classen $^{1,2} \cdot$ Melanie Stecher $^{1,2} \cdot$ Maximilian Schons $^{1}$. Christoph Spinner ${ }^{2,31}$. Jörg Janne Vehreschild ${ }^{1,2,32}$

1 Department I for Internal Medicine, University Hospital of Cologne, University of Cologne, Cologne, Germany

2 German Center for Infection Research (DZIF), Brunswick, Germany

3 Department of Infectious Diseases and Infection Control, Ingolstadt Hospital, Ingolstadt, Germany

4 Department of Internal Medicine, Infectious Diseases, Goethe University Frankfurt, Frankfurt, Germany

5 Technical University Munich, Children's Hospital, Munich, Germany

6 Research Unit Gene Vectors, Helmholtz Zentrum Muenchen, Munich, Germany

7 Clinic for Pneumology, Infectiology, Internal Medicine and Intensive Care, Hospital Dortmund gGmbH, Dortmund, Germany
8 Department of Gastroenterology and Infectiology, Heidelberg University Hospital, Heidelberg, Germany

9 Department of Internal Medicine, University Hospital Schleswig-Holstein, Kiel, Germany

10 Department of Gastroenterology and Infectiology, Klinikum Ernst-von-Bergmann, Potsdam, Germany

11 Emergency Department, University Hospital Regensburg, Regensburg, Germany

12 Department of Medicine II, University of Freiburg, Freiburg, Germany

13 University Clinic for Haematology, Oncology, Haemostaseology and Palliative Care, University of Bochum, Minden, Germany

14 Division of Infectious Diseases, Department of Internal Medicine III, University Hospital of Ulm, Ulm, Germany 
15 Division of Infectious Diseases, Department of Medicine II, University of Würzburg Medical Center, Würzburg, Germany

16 Center of Infectiology Berlin/Prenzlauer Berg, Berlin, Germany

17 Department of Neurology, Katholisches Klinikum Bochum, Ruhr University Bochum, Bochum, Germany

18 4th Department of Internal Medicine, Klinikum Leverkusen gGmbH, Leverkusen, Germany

19 Department of Infectious Diseases, University Hospital Essen, University Duisburg-Essen, Essen, Germany

20 Bundeswehr Central Hospital, Koblenz, Germany

21 Department of Internal Medicine III, Ludwig Maximilians University, Munich, Germany

22 German Cancer Consortium (DKTK), partner site Munich, Munich, Germany

23 Bavarian Center for Cancer Research (BZKF), Munich, Germany

24 2nd Medical Clinic, Hospital Passau, Passau, Germany
25 Department of Medicine 1, University Hospital Erlangen, Erlangen, Germany

26 Medical Clinic II, University Hospital Gießen, Giessen, Germany

27 Division of Infectious Diseases, University Hospital Carl Gustav Carus, Technical University of Dresden, Dresden, Germany

28 Department of Internal Medicine II, University Hospital Jena, Jena, Germany

29 Department of Haematology, Haemostasis, Oncology and Stem Cell Transplantation, Hannover Medical School, Hannover, Germany

30 Department of Internal Medicine I, UKB University Hospital Bonn, Bonn, Germany

31 Department of Internal Medicine II, School of Medicine, Technical University of Munich, University Hospital Rechts Der Isar, Munich, Germany

32 Department of Internal Medicine, Hematology and Oncology, Goethe University Frankfurt, Frankfurt, Germany 